\title{
Assessment of the AERMOD dispersion model over complex terrain with different types of meteorological data: Tracy Power Plant experiment
}

\author{
Mateusz Rzeszutek ${ }^{1,}{ }^{*}$, Adriana Szulecka ${ }^{1}$, Robert Oleniacz ${ }^{1}$, and Marek Bogacki ${ }^{1}$ \\ ${ }^{1}$ AGH University of Science and Technology, Department of Environmental Management and \\ Protection, Al. Mickiewicza 30, 30-059 Krakow, Poland
}

\begin{abstract}
The accuracy of air pollutants dispersion modelling results depends on the quality of the input data, including the representativeness of the meteorological data. The paper presents the results of the AERMOD model validation using data from Tracy Power Plant experiment (Nevada, USA) with various meteorological data sources, including WRF modelling system outputs. The highest efficiency of the AERMOD model performance was found using site-specific meteorological data and the results from the WRF model. In general, the AERMOD modelling system inadequately represents the concentration levels of tracer gas $\left(\mathrm{SF}_{6}\right)$ at receptors situated below the emitter height in areas of complex topography.
\end{abstract}

\section{Introduction}

AERMOD is an air pollutant dispersion model developed by the American Meteorological Society (AMS) / Environmental Protection Agency (U.S. EPA) for regulatory purposes in the near field studies (up to $50 \mathrm{~km}$ ) and complex terrain [1]. It is a steady-state model, in which the plume of emitted pollutants spreads both horizontally and vertically in accordance with the Gaussian distribution [2]. The model is adapted for air pollutant dispersion modelling in complex terrain with the variability of vertical wind profile, temperature and turbulences in the planetary boundary layer (PBL) taken into account [3]. It belongs to the second generation of dispersion models in which Gaussian formulations are used for stable conditions, and for unstable situations a semi-empirical approach is adopted [4].

Fundamental concern during modelling in complex terrain is involved with limited availability of representative meteorological data that can be used in the model. Most conducted field experiments that aimed at the AERMOD validation, were carried out using site-specific meteorological data, including temperature and wind field information in the vertical profile [3], [5-7]. More often, however, access to such representative meteorological data is limited. Therefore, the results of calculations using prognostic meteorological models are increasingly used as input data to the AERMOD model [8-11].

\footnotetext{
*Corresponding author: rzeszut@agh.edu.pl
} 
The guidelines on air quality models [1] allow the use of prognostic meteorological data if their quality is acceptable and both site-specific and National Weather Service (NWS) data are unavailable or impossible to collect.

Previous studies concerning the integration of AERMOD and WRF models [9] have shown, that prognostic meteorological data perform well compared to the site-specific measurements. However, in these studies and in the case of the work [4-5], the analysis of the AERMOD performance was limited to the high-end concentrations that are important from the perspective of legal regulations. Such approach may be insufficient, since many researches use coupled AERMOD dispersion model with WRF to achieve different goals $[8,10,11]$. Furthermore, three of the experiments conducted in the study [9] referred to a small number of receptors (2 to 7). Instead of stable and non-reactive tracer gas, the $\mathrm{SO}_{2}$ and $\mathrm{Pb}$ were used, for which both the determination of the emission rates and background concentrations may be a source of additional uncertainty, as highlighted by Dresser and Huizer [6].

Therefore, in the study, a more detailed evaluation of the AERMOD modelling system was conducted in the area of complex topography using Tracy Power Plant experiment (based on 106 receptors and $\mathrm{SF}_{6}$ as a tracer gas) considering different sources of meteorological data, including those derived from the WRF model.

\section{Materials and methods}

\subsection{Description of Tracy Power Plant experiment}

The Tracy Power Plant experiment is one of four campaigns commissioned by U.S. EPA for the development of dispersion models in irregular mountainous areas [12, 13]. Tracy power plant is located east of Reno (Nevada) in the Truckee River valley, surrounded by mountain peaks reaching relative height of $950 \mathrm{~m}$ (Fig. 1).

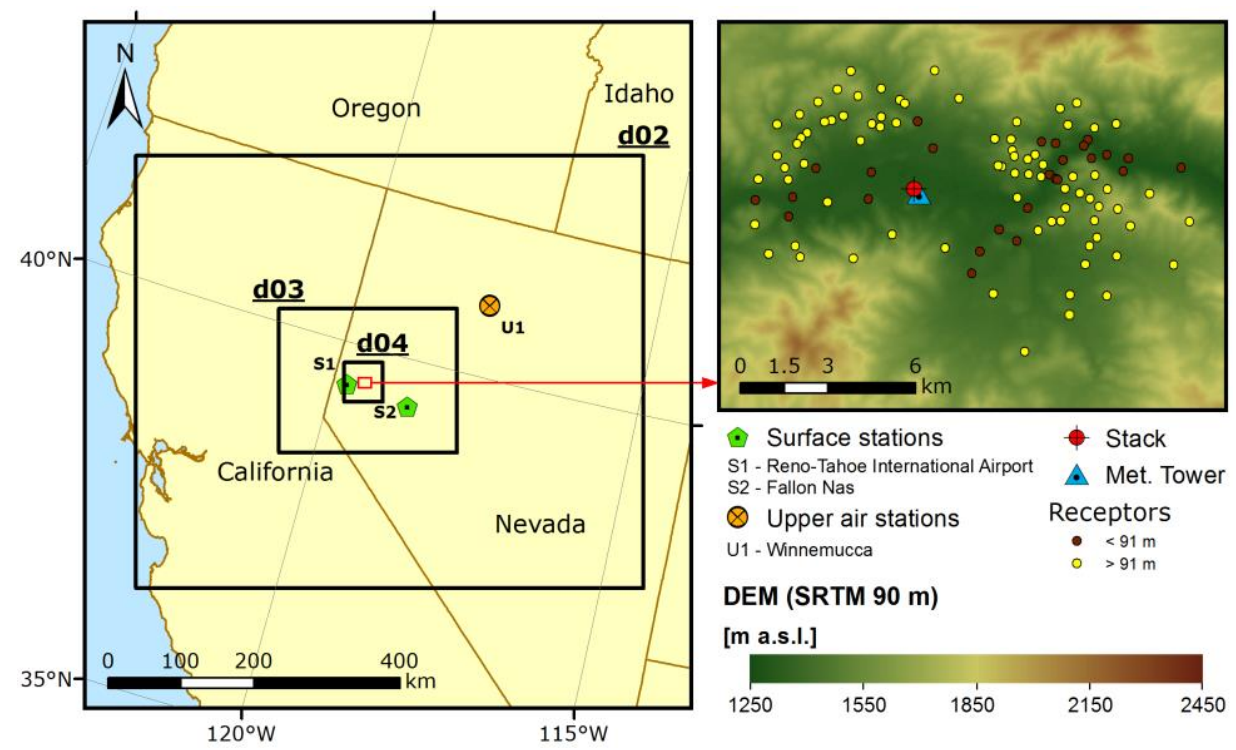

Fig. 1. Location of the emitter and measurement points used in the Tracy Power Plant experiment with the boundaries of three inner domain (d02-d04) in the WRF model 
Field trials in this experiment were conducted in August 1984 using $\mathrm{SF}_{6}$ tracer gas. This marker was released into the atmosphere through a $91-\mathrm{m}$ power plant stack. The experiment was carried out in 14 single campaigns, during which a series of 128 hours of data was collected at 106 receptors located both below and above the emitter height (26 and 80 receptors, respectively). Meteorological measurements were collected from an instrumented $150-\mathrm{m}$ tower and extended above this height using a Doppler acoustic sounder and a tethersonde $[12,14]$.

\subsection{Configuration of the WRF model and simulation design}

Simulation of meteorological parameters in this study was performed using the WRF v3.7 modelling system described in [15]. Initial and boundary meteorological conditions were provided using NCEP North American Regional Reanalysis dataset (ds608.0) [16] produced every 3 hours. This dataset was chosen due to its fine spatial resolution $(32 \times 32$ $\mathrm{km}$ ) and the availability for the period of Tracy Power Plant experiment. The simulation was performed in the coarse domain (d01) comprising the territory of the western USA with a spatial resolution of $36 \times 36 \mathrm{~km}$. Three one-way nested domains with the following resolutions: $12 \times 12 \mathrm{~km}(\mathrm{~d} 02), 4 \times 4 \mathrm{~km}(\mathrm{~d} 03)$ and $1 \times 1 \mathrm{~km}(\mathrm{~d} 04)$ were set to include the area of research (Fig. 1). The calculations were conducted at 44 assigned vertical levels with the lowest layer of $20 \mathrm{~m}$ above ground to ensure comparability with observations from meteorological tower.

\subsection{Settings and computational variants in AERMOD}

In the study a number of model simulations were carried out with respect to various meteorological data. Table 1 summarizes the computational variants with a short description of used meteorological data.

Table 1. Description of calculation variants with regard to the input data

\begin{tabular}{|c|c|c|}
\hline Variant & Description of meteorological data & Tools \\
\hline FW & Fallon Nas (S2) and Winnemucca (U1) & AERMET \\
\hline RW & Reno - Tahoe International Airport (S1) and Winnemucca (U1) & AERMET \\
\hline RWO-L & $\begin{array}{c}\text { Reno - Tahoe International Airport (S1), Winnemucca (U2) and } \\
\text { only 10 m layer from meteorological tower }\end{array}$ & AERMET \\
\hline RWO-R & $\begin{array}{c}\text { Reno - Tahoe International Airport (S1), Winnemucca (U2), all } \\
\text { layers from meteorological tower and Doppler acoustic sounder }\end{array}$ & AERMET \\
\hline WRF1 & From WRF, domain with the resolution of 1x1 km (d04) & MMIF/AERMET \\
\hline WRF4 & From WRF, domain with the resolution of $4 \times 4 \mathrm{~km}(\mathrm{~d} 03)$ & MMIF/AERMET \\
\hline
\end{tabular}

Meteorological data from surface stations (S1, S2), upper air (U1) and meteorological tower were processed using AERMET v15181 preprocessor to determine planetary boundary layer parameters, such as the Monin-Obukhov length, convective velocity scale, temperature scale, mixing height, and surface heat flux. Subsequently, they were preprocessed using AERMET in accordance with the U.S. EPA guidelines $[1,17]$. The only exception was the height of vertical layers, which were assigned in accordance to the height of the meteorological tower measurements. Calculations of $\mathrm{SF}_{6}$ atmospheric dispersion were conducted using AERMOD v15181 with Complex Terrain Algorithms [3]. 


\subsection{Comparison of meteorological data and model evaluation methods}

Validation of meteorological conditions was limited to 128 hours of valid meteorological tower observations. Calculation period was synchronized with the measurement time at the tower. The comparative analysis was based on the wind field representation from meteorological stations (at $10 \mathrm{~m}$ a.g.1.), meteorological tower (at 10 and $100 \mathrm{~m}$ a.g.l.) and the WRF modelling results at the location of meteorological tower (at $100 \mathrm{~m}$ a.g.1.). Final verification of WRF modelling outputs compliance with meteorological tower observations was based on the analysis of wind field displacement (WD) calculated as reported in [9].

Evaluation of the AERMOD model with respect to different meteorological data sources was conducted to determine the ability to predict the upper tail end concentration distributions and to represent the distribution of observed 1-hour concentrations. Model capability to predict the high-end distribution of the highest 1-hour concentrations was analysed using Robust Highest Concentration (RHC) values [18]. The evaluation of model ability to predict the 1-hour concentration distribution was conducted on the subset of 200 of the highest 1-hour concentrations using statistical model evaluation parameters: FB (Fractional Bias), NMSE (Normalized Mean Square Error), NAD (Normalized Absolute Difference) and FAC2 (Factor of Two of Observations). For calculation of these parameters the quantitative limitation of the sample was applied because of the impossibility to determine the appropriate lower concentration threshold. Attempts to establish the lower limit of compared concentrations resulted in significant differences of sample sizes [19].

\section{Results and discussion}

\subsection{Comparison of meteorological data}

Near surface wind field varies significantly in complex terrain, as it highly depends on the terrain features and local airflows (e.g. slope and valley winds) induced by cyclic changes in the amount of energy reaching the surface of the earth [20,21]. High variability of surface wind speed and direction during the experiment in the area of study is shown in Fig. 2. Considered surface weather stations S1 and S2 are located 22.3 and $68.9 \mathrm{~km}$ from the emission source, respectively, and the dominant wind direction varies from WS direction at the meteorological tower location to SE and WN at the location of S2 surface station. Mean wind speed is also lower for the meteorological tower observations $\left(1.67 \mathrm{~m} \mathrm{~s}^{-1}\right)$ during experimental campaigns compared to the measurements at S1 and S2 stations (2.48 and $2.15 \mathrm{~m} \mathrm{~s}^{-1}$, respectively).

Wind roses obtained at the height of $100 \mathrm{~m}$ a.g.l. (Fig. 3) show, that the WRF model inaccurately represents dominant directions of wind flow at the location of meteorological tower, but in general mean wind speed values are comparable with observations. Overall, the WRF model performance was considered to be acceptable, as the values of wind field displacement calculated at $10 \mathrm{~m}$ a.g.l. do not exceed the spatial resolution of modelling domains (reaching $0.889 \mathrm{~km}$ for WRF1 and $0.877 \mathrm{~km}$ for WRF4). Nested grid with a higher spatial resolution does not improve the accuracy of wind field characteristics, which, to a certain degree, may result from model configuration [22]. 


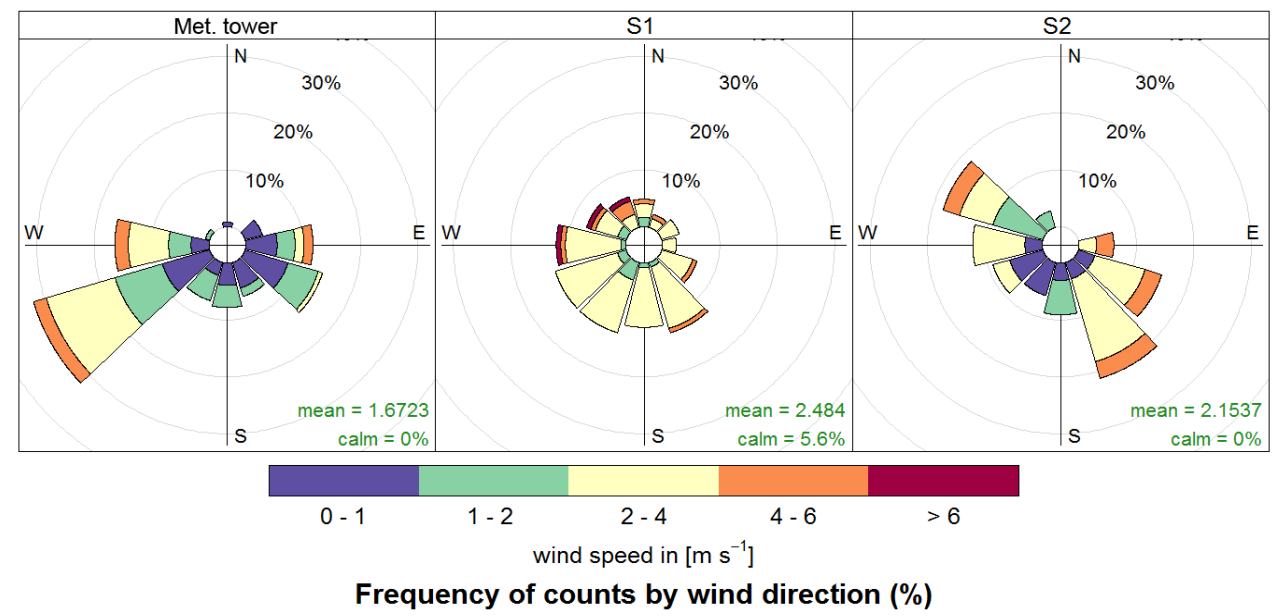

Fig. 2. Wind roses at the height of $10 \mathrm{~m}$ a.g.l. for meteorological tower, S1 and S2 meteorological stations

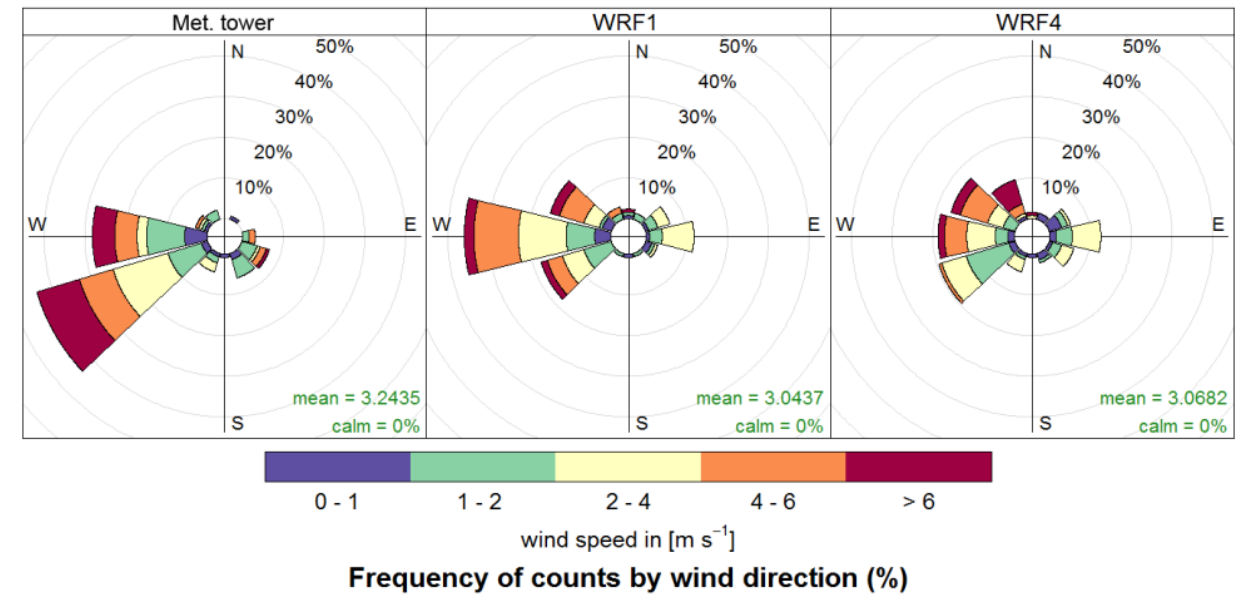

Fig. 3. Wind roses at the height of $100 \mathrm{~m}$ a.g.l. for meteorological tower observations and the results of WRF modelling at the tower location

\subsection{Evaluation of the AERMOD model with regard to the maximum values}

Determined statistical parameters of the model evaluation (Tab. 2) indicate that for the most of concerned calculation variants, the AERMOD model accurately represents the high-end distribution of the highest 1-hour concentrations both for the whole sample (all receptors) and for receptors located only above the emitter height (relatively high comparability of modelled and observed RHC values). Similar conclusions, but with no receptor grouping performed and using only site-specific data are presented in [5-7], [14] as well. The RWO$\mathrm{L}$ and RW variants are the only exceptions for which the value of $|\mathrm{FB}|$ is greater than 0.3 and therefore falls outside the limits of good air quality models for rural areas as specified in [19]. The assessment results for the RWO-L variant indicate a strong, even 3-fold overestimation of modelled values, which results directly from the large difference in average wind speed between 10 and $100 \mathrm{~m}$ (Fig. 2 and 3). It should be noted that the use of meteorological data from surface stations (at $10 \mathrm{~m}$ a.g.l.) representative in terms of the location, will not provide adequate results for air pollutants dispersion modelling for 
regulatory purposes. Therefore, the meteorological representativeness of input data for the AERMOD model according to the guidelines [1] should refer to the vertical wind field data as well.

Table 2. One-hour $\mathrm{RHC}_{\mathrm{m}}$ (modelled) compared with $\mathrm{RHC}_{\mathrm{o}}$ (observed) in $\mu \mathrm{g} \mathrm{m}^{-3}$ for analysed variants and groups denoting receptor location

\begin{tabular}{|c|c|c|c|c|c|c|c|c|c|}
\hline \multirow{2}{*}{ Variant } & \multicolumn{3}{|c|}{ All receptors } & \multicolumn{3}{c|}{ Receptors <91 m } & \multicolumn{3}{c|}{ Receptors >91 m } \\
\cline { 2 - 11 } & $\mathrm{RHC}_{\mathrm{m}}$ & Ratio $^{*}$ & $\mathrm{FB}$ & $\mathrm{RHC}_{\mathrm{m}}$ & Ratio* $^{\mathrm{F}}$ & $\mathrm{FB}$ & $\mathrm{RHC}_{\mathrm{m}}$ & Ratio* $^{*}$ & $\mathrm{FB}$ \\
\hline $\mathrm{FW}$ & 13.92 & 0.93 & 0.07 & 0.91 & 0.10 & 1.65 & 13.92 & 1.03 & -0.03 \\
\hline RW & 8.80 & 0.59 & 0.52 & 1.48 & 0.16 & 1.45 & 8.67 & 0.64 & 0.43 \\
\hline RWO-L & 42.24 & 2.82 & -0.95 & 12.98 & 1.38 & -0.32 & 42.91 & 3.18 & -1.04 \\
\hline RWO-R & 13.07 & 0.87 & 0.14 & 4.98 & 0.53 & 0.61 & 12.56 & 0.93 & 0.07 \\
\hline WRF4 & 17.57 & 1.17 & -0.16 & 2.84 & 0.30 & 1.07 & 17.57 & 1.30 & -0.26 \\
\hline WRF1 & 13.70 & 0.91 & 0.09 & 2.14 & 0.23 & 1.26 & 13.70 & 1.02 & -0.02 \\
\hline RHC $_{0}$ & \multicolumn{3}{|c|}{14.98} & & & 9.38 & & 13.49 & \\
\hline
\end{tabular}

* $\mathrm{RHC}_{\mathrm{m}} / \mathrm{RHC}_{\mathrm{o}}$

The analysis show, that the prognostic meteorological input data can be used for regulatory purposes, as most concentrations calculated in the AERMOD model for the WRF variants are characterized by slight overestimation. It is indicated by negative value of FB that stays within the limits of good air quality models. However, studies described in [9] show, that the use of WRF data does not always lead to the overestimation of the highest 1-hour observations, and the site-specific data generally yield better results. On the other hand, the use of data derived only from the NWS stations located at a great distance from the emission source (for which, as indicated in Section 3.1, the wind field differs significantly compared to the meteorological tower observations), can yield both good (FW) and poor (RW) results. Acceptable quality of the FW variant results is probably related to the several occurrences of similar meteorological events responsible for the highend distribution of the highest 1-hour concentrations. Therefore, the RHC parameter is not sufficient to clearly determine which of the analysed solutions is appropriate.

The outcomes obtained for receptors below the emitter height indicate that AERMOD poorly represents the actual concentration levels at these points, generally with significant underestimation of the results. This behaviour of the model is disturbing, especially considering the use of the AERMOD model for regulatory purposes over complex terrain.

\subsection{Similarity assessment of the 1-hour concentration distributions}

Distributions of 200 of the highest observed concentrations with respect to the modelled values for analysed calculation variants (Fig. 4) generally confirm the conclusions drawn in Section 3.2. However, they show that the use of data from NWS (the RW and FW variants) generally results in a large number of significantly underestimated values. Despite the fact that the upper part of 1-hour concentrations distribution is similar to the observations for the $\mathrm{FW}$, the remaining results are strongly underestimated (at least 2-fold). 

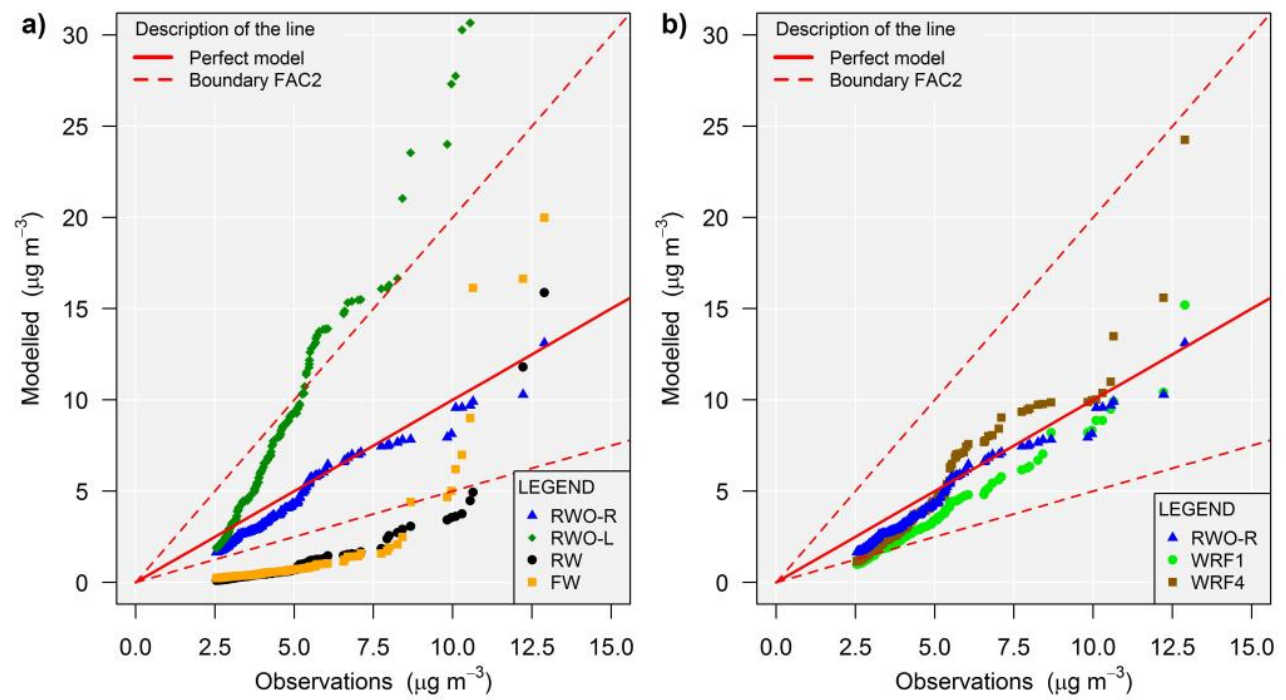

Fig. 4. Q-Q plots for the AERMOD results (200 of the highest 1-hour concentrations) corresponding to different meteorological input data for Tracy Power Plant experiment: a) site specific (all layers and one layer) and surface meteorological data, b) site-specific (all layers) and WRF meteorological data

With regulatory purposes of the AERMOD model kept in mind, it should be noted that the calculation results of concentrations ought to be rather slightly overestimated than underestimated [7]. Such results were obtained using the WRF meteorological data at the spatial resolution of $4 \times 4 \mathrm{~km}$ (Fig. 4). The outcomes indicate the use of coarser WRF input data from $4 \mathrm{~km}$ grid instead of $1 \mathrm{~km}$ grid may be a better solution, since the WRF model does not always produce better results for finer resolution grids in the areas of complex orography and without additional data assimilation [21]. This is confirmed by the values of statistical model evaluation parameters (Tab. 3) for receptors located above the emitter height, as they are noticeably worse for the WRF1 compared to the WRF4 variant.

Table 3. Selected parameters for statistical evaluation of dispersion model evaluation for analysed variants and groups denoting receptor location

\begin{tabular}{|c|c|c|c|c|c|c|c|c|}
\hline \multirow{2}{*}{ Variant } & \multicolumn{4}{|c|}{ Receptors <91 m } & \multicolumn{4}{c|}{ Receptors >91 m } \\
\cline { 2 - 10 } & FAC2 & FB & NMSE & NAD & FAC2 & FB & NMSE & NAD \\
\hline FW & 0.00 & 1.84 & 30.21 & 0.92 & 0.05 & 1.23 & 3.03 & 0.65 \\
\hline RW & 0.00 & 1.79 & 20.92 & 0.90 & 0.01 & 1.41 & 4.38 & 0.71 \\
\hline RWO-L & 0.08 & 0.89 & 1.46 & 0.51 & 0.82 & -0.56 & 1.32 & 0.29 \\
\hline RWO-R & 0.01 & 0.99 & 1.54 & 0.50 & 1.00 & 0.12 & 0.02 & 0.07 \\
\hline WRF4 & 0.00 & 1.59 & 8.38 & 0.79 & 0.95 & 0.10 & 0.14 & 0.14 \\
\hline WRF1 & 0.00 & 1.55 & 7.67 & 0.77 & 0.72 & 0.36 & 0.15 & 0.19 \\
\hline
\end{tabular}

The results shown in Table 3 indicate, that the most accurate results were obtained for receptors located at the height exceeding 91 meters using site-specific meteorological data 
and for $4 \mathrm{~km}$ grid from the WRF model. For both of these variants, the statistical evaluation parameters meet the acceptance criteria for dispersion models in rural areas [19]. Therefore, the application of WRF model as the substitution in the absence of representative NWS and site-specific measurements in complex terrain is appropriate, as indicated in recent update of the guidelines on air quality models [1].

However, the above statements refer only to receptors located above the height of the emission source, similarly as in the work [9], and the model assessment indicate that the AERMOD model underestimates concentrations for receptors below the emitter height for all of the considered variants. Findings in the corresponding studies conducted for simple terrain experiments [5, 14] provide opposite conclusions. However, it should be emphasized that in the Tracy Power Plant experiment used in the study, many receptors below the emitter height were located in the valley behind the mountain ridges (Fig. 1), and the formulations used in AERMOD for complex terrain applications are not suitable for these situations [3]. This fact may constitute a significant problem, since the highest concentrations are not always associated with the receptors located above the emitter height, and the calculation results for those below the emitter will be underestimated, even with the use of measurements from the near surface atmospheric layer.

\section{Summary}

The results of calculations and analysis presented in the study allow to conclude, that the use of site-specific and the WRF model meteorological data is appropriate for air dispersion modelling using the AERMOD model for complex terrain applications. The use of the data from $4 \mathrm{~km}$ grid is suggested, as there is no improvement in the quality of modelling results and the computational costs increase significantly for finer resolutions. According to the U.S. EPA guidelines [1], the application of the WRF model in air dispersion modelling for regulatory purposes is recommended. However, this approach is appropriate in the absence of spatially representative meteorological data and with lack of information about the wind field characteristics in the vertical profile of the atmosphere.

For the Tracy Power Plant experiment results, a strong underestimation of concentrations at receptors below the emitter height was found. This is probably associated with the large number of receptors belonging to this group and located in the valleys between the mountain ranges, but a proper explanation of the cause of this issue requires further and more detailed research in the areas of complex topography.

Additionally, the analysis carried out in the study indicate, that the use of RHC parameter alone provide insufficient information to determine which set of meteorological data contributes to better performance of the dispersion model. Furthermore, the assessment focused solely on the analysis of the high-end distribution of the highest 1-hour concentrations may be conditioned by the accidental occurrences of several similar meteorological events responsible for these concentrations.

The paper has been prepared within the scope of the AGH UST statutory research no. 11.11.150.008.

\section{References}

1. U.S. EPA, Revisions to the Guideline on Air Quality Models: Enhancements to the AERMOD Dispersion Modeling System and Incorporation of Approaches to Address Ozone and Fine Particulate Matter (Federal Register, 40 CFR Part 51, Appendix W, 2017) 
2. A.J. Cimorelli, S.G. Perry, A. Venkatram, J.C. Weil, R.J. Paine, R.B. Wilson, R.F. Lee, W.D. Peters, R.W. Brode, J. Appl. Meteorol., 44, pp. 682-693 (2005)

3. A. Venkatram, R.W. Brode, A.J. Cimorelli, R.F. Lee, R.J. Paine, S.G. Perry, W.D. Peters, J.C. Weil, R.B. Wilson, Atmos. Environ., 35, pp. 4211-4221 (2001)

4. K. Juda-Rezler, Arch. Environ. Prot., 36, 1, pp. 3-28 (2010)

5. S.G. Perry, A.J. Cimorelli, R.J. Paine, R.W. Brode, J.C. Weil, A. Venkatram, R.B. Wilson, R.F. Lee, W.D. Peters, J. Appl. Meteorol., 44, 5, pp. 694-708 (2005)

6. A.L. Dresser, R.D. Huizer, J. Air Waste Manage. Assoc., 61, 6, pp. 647-659 (2011)

7. A.S. Rood, Atmos. Environ., 89, pp. 707-720 (2014)

8. G.A. Abril, S.C. Diez, M.L. Pignata, J. Britch, Atmos. Pollut. Res., 7, 1, pp. 180-189 (2016)

9. U.S. EPA, Evaluation of Prognostic Meteorological Data in AERMOD Applications (Report EPA-454/R-16-004, Research Triangle Park, NC 27711, 2016)

10. A. Kumar, R.S. Patil, A.K. Dikshit, S. Islam, R. Kumar, J. Clean. Prod., 116, pp. 1-8, (2015)

11. L. Turtos Carbonell, G.C. Mastrapa, Y.F. Rodriguez, L. Alvarez Escudero, M. Sanchez Gacita, A B. Morlot, I.B. Montejo, E.M. Ruiz, S.P. Rivas, L.T. Carbonell, Atmos. Pollut. Res., 4, 1, pp. 64-74 (2013)

12. L.E. Truppi, EPA complex terrain model development: Description of a computer data base from the full scale plume study, Tracy Power Plant, Nevada (Report EPA/600/S386/068, Research Triangle Park, NC 27711, 1987)

13. U.S. EPA, Support Center for Regulatory Atmospheric Modeling - Preferred and Recommended Models (available at: https://www.epa.gov/scram/air-quality-dispersionmodeling-preferred-and-recommended-models, accessed: 25-mar-2017)

14. U.S. EPA, AERMOD: Latest features and evaluation results (Report EPA-454/B-03001, Research Triangle Park, NC 27711, 2003)

15. W.C. Skamarock, J.B. Klemp, J. Dudhi, D.O. Gill, D.M. Barker, M.G. Duda, X.-Y. Huang, W. Wang, J.G. Powers, A Description of the Advanced Research WRF Version 3 (Report NCAR/TN-475+STR, Boulder, CO, 2008)

16. F. Mesinger, G. DiMego, E. Kalnay, K. Mitchell, P.C. Shafran, W. Ebisuzaki, D. Jovic, J. Woollen, E. Rogers, E.H. Berbery, M.B. Ek, Y. Fan, R. Grumbine, W. Higgins, H. Li, Y. Lin, G. Manikin, D. Parrish, W. Shi, Bull. Am. Meteorol. Soc., 87, 3, pp. 343 360 (2006)

17. U.S. EPA, Guidance on the Use of the Mesoscale Model Interface Program (MMIF) for AERMOD Applications (Report EPA-454/B-15-001, Research Triangle Park, NC 27711, 2016)

18. W.M. Cox, J.A. Tikvart, Atmos. Environ., 24A, 9, pp. 2387-2395 (1990)

19. S. Hanna, J. Chang, Atmos. Phys., 116, 3-4, pp. 133-146 (2012)

20. L. Giovannini, D. Zardi, M. de Franceschi, F. Chen, Int. J. Climatol., 34, 4, pp. 11111131 (2014)

21. L. Giovannini, G. Antonacci, D. Zardi, L. Laiti, L. Panziera, Energy Procedia, 59, pp. 323-329 (2014)

22. Y. Zhang, X. Zhang, L. Wang, Q. Zhang, F. Duan, K. He, Atmos. Environ., 124, pp. 285-300 (2016) 